\title{
Tracheostomy in Infants With Congenital Heart Disease: A Nationwide Population-Based Study in Taiwan
}

\author{
Yu-Sheng Lee MD MSc PhD, Mei-Jy Jeng MD PhD, Pei-Chen Tsao MD MSc, \\ Wen-Jue Soong MD, and Pesus Chou DrPH
}

\begin{abstract}
BACKGROUND: This study aimed to use the National Health Insurance Research Database in Taiwan to examine the risk factors for tracheostomy in infants with congenital heart disease (CHD) and to evaluate the associated mortality risk in those who received a tracheostomy. METHODS: The study was conducted between 2000 and 2011 with infants assigned to either a CHD group (34,943 subjects) or an age- and sex-matched control group (136,600 subjects). We then performed descriptive, logistic regression, Kaplan-Meier, and Cox regression analyses for the investigation. RESULTS: Infants with CHD had an increased risk of tracheostomy (adjusted hazard ratio [HR], 6.67, 95\% CI 4.40-10.10). Congenital airway anomaly (adjusted odds ratio [OR], 15.25, 95\% CI 10.56-22.02), neuromuscular impairment (adjusted OR 6.24, 95\% CI 4.35-8.94), and time (0-3 y) after CHD diagnosis (adjusted OR 3.27, 95\% CI 2.19-4.89) were most highly correlated with tracheostomy placement. The mortality risk was increased in infants with CHD and a tracheostomy even after adjusting for confounders (adjusted HR 3.88, 95\% CI 2.96-5.08). Mortality risk (adjusted HR and 95\% CI) increased by $2.06(1.56-2.71), 7.19$ (2.42-21.38), and $14.76(1.46-149.69)$ after 0-3, 4-7, and 8-11 y of follow-up, respectively. CONCLUSIONS: Infants with CHD had an increased risk of undergoing tracheostomy. The mortality risk is significantly increased in infants with CHD and tracheostomy, and the risk increases progressively with time. Further studies are warranted to clarify the mechanisms underlying the risks associated with tracheostomy. Key words: congenital heart disease; hazard ratio; national health insurance; national health insurance research database; odds ratio; tracheostomy. [Respir Care 2016;61(7):958-964. (c) 2016 Daedalus Enterprises]
\end{abstract}

\section{Introduction}

Congenital heart disease (CHD) is one of the common major congenital anomalies with a reported birth preva-

\footnotetext{
Drs Lee, Jeng, Tsao, and Soong are affiliated with the Department of Pediatrics, Taipei Veterans General Hospital, Taipei, Taiwan and the Department of Pediatrics, National Yang-Ming University School of Medicine, Taipei, Taiwan. Dr Lee is also affiliated with the Institute of Public Health and Community Medicine Research Center, National, Yang-Ming University School of Medicine, Taipei, Taiwan. Dr Jeng is also affiliated with the Institute of Emergency and Critical Care Medicine, National Yang-Ming University, School of Medicine, Taipei, Taiwan. Dr Chou is affiliated with the Institute of Public Health and Community Medicine Research Center, National, Yang-Ming University School of Medicine, Taipei, Taiwan.
}

Supplementary material related to this paper is available at http:// www.rcjournal.com.

This study was supported by grant funding from Taipei Veterans General Hospital (V102B-047), Taiwan. The authors have disclosed no conflicts of interest. lence of 5-8/1,000 live births. ${ }^{1-3}$ Progress in neonatology, intensive care, pediatric cardiology, and cardiovascular surgery means that CHD is no longer considered fatal, and favorable outcomes can often be achieved. ${ }^{4}$ Therefore, it is crucial to explore the risk factors associated with CHD morbidity and mortality to optimize quality of life.

Tracheostomies can be lifesaving procedures following severe respiratory compromise. ${ }^{5,6}$ Although infections have historically been the most common indication, ${ }^{7}$ tracheos-

Drs Chou and Soong contributed equally to this work.

Correspondence: Pesus Chou DrPH, Institute of Public Health and Community Medicine Research Center, National Yang-Ming University, No. 155, Sec. 2, Li-Nong Street, Taipei 112, Taiwan. E-mail: pschou@ym.edu.tw. Wen-Jue Soong MD, Department of Pediatrics, Taipei Veterans General Hospital, No. 201, Sec. 2 Shih-Pai Road, Taipei 112, Taiwan. E-mail: wjsoong@vghtpe.gov.tw.

DOI: $10.4187 /$ respcare. 04266 
tomies are increasingly indicated for prolonged ventilator dependence in children with chronic complex health conditions. ${ }^{6,8-12}$ However, most studies have focused on the indications for tracheostomy, the subsequent outcomes, or resource utilization. ${ }^{6,10-22}$ Data are scant regarding the epidemiological risk factors for tracheostomy in CHD, and there have been no large-scale population-based studies. Furthermore, among infants with CHD requiring a tracheostomy, previous studies have failed to investigate either the overall mortality risk or the mortality risk stratified by a follow-up period. This study aimed to use the National Health Insurance Research Database in Taiwan to examine the risk factors for tracheostomy in infants with CHD and to evaluate the associated mortality risk in those who received a tracheostomy.

\section{Methods}

\section{Ethical Statement}

The institutional review board of Taipei Veterans General Hospital, Taiwan, approved this study (2014-08005AC). Because all personal identifying information had been encrypted before the database was released, the review board waived the requirement for written informed consent.

\section{Data Sources}

This study was based on data from the National Health Insurance Research Database released by the National Health Research Institute. Enrollment in Taiwan's national health insurance program is mandatory, and data are currently available for $>23$ million people, representing approximately $99 \%$ of Taiwan's population. ${ }^{23}$ The National Health Insurance Research Database includes the entire registry and original reimbursement claims data for each national health insurance enrollee in Taiwan. With extensive data for medical care reimbursement claims, the National Health Insurance Research Database provides a large and comprehensive national data set. The diagnostic codes used in the National Health Insurance Research Database are in the format of the International Classification of Diseases, 9th Revision, Clinical Modification (ICD-9-CM), as established by physicians and previously validated. ${ }^{24-26}$

All information that may identify subject information was encrypted, and confidentiality was maintained in accordance with the data regulations of the National Health Insurance Administration, the Ministry of Health and Welfare, and the National Health Research Institute. The National Health Research Institute guards the privacy of all beneficiaries and provides the National Health Insurance Research Database to researchers who have obtained ethical approval.

\section{QUICK LOOK}

\section{Current knowledge}

Tracheostomies are increasingly indicated for prolonged ventilator dependence in children with chronic complex health conditions. Most studies have focused on the indications for tracheostomy, the subsequent outcomes, or resource utilization. Data are scant regarding the epidemiological risk factors for tracheostomy in congenital heart disease (CHD), and there have been no large-scale population-based studies.

\section{What this paper contributes to our knowledge}

We demonstrated that subjects with CHD had a 6.67 times higher risk of tracheostomy than those without CHD. Tracheostomies were more common among those with congenital airway anomaly and neuromuscular impairment and were most likely to be needed within the first $0-3$ y after CHD diagnosis. Mortality risk was also elevated following tracheostomy in infants with CHD, with an adjusted hazard ratio of 3.88 after a mean 6.4-y follow-up period. Over time, there was a decrease in the risk of tracheostomy and an increase in the associated mortality risk for infants with CHD.

\section{Infants With CHD (CHD Group)}

We conducted a retrospective population-based cohort study from January 1, 2000 to December 31, 2011. Using the diagnostic codes for CHD in the National Health Insurance Research Database (ICD-9-CM 745, 746, 747.04), we identified 34,943 infants $<1$ y old born after January 1,2000 . The first date for each subject's CHD diagnosis, as recorded in the National Health Insurance Research Database, was defined as the index date. Information regarding the sex, age at CHD diagnosis, follow-up period, comorbid disease, and in-hospital mortality was collected for analysis. The age at CHD diagnosis was subclassified by neonatal (newborn up to $28 \mathrm{~d}$ ) and infant (age $>4$ weeks but $<12$ months) periods.

Based on previous reports, ${ }^{6,11,27,28}$ we evaluated the following comorbidities: congenital airway anomaly (ICD9-CM 748), chromosomal anomaly (ICD-9-CM 758), prematurity (ICD-9-CM 765), neuromuscular impairment (ICD-9-CM 318, 330, 334, 335, 343, 359, 740-742, 754-756) (see the supplementary appendix at http://www.rcjournal. com), and chronic lung disease (ICD-9-CM 770.7). The comorbidities were identified using the data linkage for each infant from the National Health Insurance Research Database. Infants who received a tracheostomy were 


\section{Tracheostomy in Infants With Congenital Heart Disease}

Table 1. Demographic and Clinical Characteristics of the Congenital Heart Disease and Control Groups

\begin{tabular}{|c|c|c|c|c|c|}
\hline \multirow{2}{*}{ Variables } & \multicolumn{2}{|c|}{$\begin{array}{l}\text { CHD Group } \\
(n=34,943)\end{array}$} & \multicolumn{2}{|c|}{$\begin{array}{l}\text { Control Group } \\
(n=136,600)\end{array}$} & \multirow{2}{*}{$P$} \\
\hline & $n$ & $\%$ & $n$ & $\%$ & \\
\hline Age & & & & & .17 \\
\hline Neonate & 22,147 & 63.4 & 86,040 & 63.0 & \\
\hline Infant & 12,796 & 36.6 & 50,560 & 37.0 & \\
\hline Sex & & & & & .64 \\
\hline Male & 17,507 & 50.1 & 68,246 & 50.0 & \\
\hline Female & 17,436 & 49.9 & 68,354 & 50.0 & \\
\hline Follow-up, mean (SD) y & $6.4(3.5)$ & & $6.7(3.3)$ & & $<.001$ \\
\hline $0-3$ y & 8,838 & 25.3 & 28,585 & 20.9 & \\
\hline $4-7 y$ & 9,177 & 26.3 & 39,090 & 28.6 & \\
\hline $8-11$ y & 16,928 & 48.4 & 68,925 & 50.5 & \\
\hline \multicolumn{6}{|l|}{ Comorbidity } \\
\hline Prematurity & 9,780 & 28.0 & 11,228 & 8.2 & $<.001$ \\
\hline NI & 2,628 & 7.5 & 2,937 & 2.2 & $<.001$ \\
\hline $\mathrm{CAA}$ & 1,541 & 4.4 & 1,134 & 0.8 & $<.001$ \\
\hline Chromosomal anomaly & 1,161 & 3.3 & 299 & 0.2 & $<.001$ \\
\hline Chronic lung disease & 720 & 2.1 & 309 & 0.2 & $<.001$ \\
\hline Tracheostomy & 144 & 0.4 & 32 & 0.02 & $<.001$ \\
\hline Mortality, overall & 2,491 & 7.1 & 1,287 & 0.9 & $<.001$ \\
\hline $\begin{array}{l}\mathrm{CHD}=\text { congenital heart disease } \\
\mathrm{NI}=\text { neuromuscular impairment } \\
\mathrm{CAA}=\text { congenital airway anomaly }\end{array}$ & & & & & \\
\hline
\end{tabular}

identified by the procedure codes 31.1 and 31.2.6,11 Mortality was defined according to the discharge status recorded in the National Health Insurance Research Database.

\section{Infants Without CHD (Control Group)}

Subjects without CHD were randomly selected from the same database and within the same observational period as subjects with CHD. Each subject with CHD was matched by age, sex, and index date with 4 subjects without CHD. In total, 136,600 infants met these criteria and served as the control group. The same variables were analyzed in both the control and CHD groups. All of the enrolled subjects were followed until their death or December 31, 2011, whichever occurred first.

\section{Statistical Analysis}

All data were linked by SQL server 2008 (Microsoft Corporation, Redmond, Washington) and analyzed by SPSS 19.0 for Windows (IBM Corporation, Armonk, New York). Continuous variables were described as mean and $\mathrm{SD}$ and were compared using independent $t$ tests. Categorical variables were described as percentages and were compared using the chi-square or Fisher exact tests as appropriate. Cox regression analyses with crude and ad- justed hazard ratios (HRs) were used to evaluate the risk for tracheostomy and the associated mortality risk among infants with CHD who received a tracheostomy. Multivariate logistic regression analyses with adjusted odds ratios (ORs) were used to assess the likelihood of tracheostomy in infants with CHD. We used Kaplan-Meier analyses and log-rank tests to estimate the cumulative incidence of mortality among infants with CHD, with and without tracheostomy. For all tests, 2 -tailed $P$ values of $<.05$ were considered statistically significant.

\section{Results}

\section{Demographic and Clinical Characteristics of the CHD and Control Groups}

We included 171,543 infants age <1 y: 34,943 with CHD and 136,600 without CHD. Most infants with CHD were diagnosed as neonates, and the most common comorbidity was prematurity, followed by neuromuscular impairment and congenital airway anomaly. Infants with CHD had significantly more comorbidities than those without CHD and underwent significantly more tracheostomies. In the CHD group, the mean follow-up period was shorter, and the mortality rate was higher (Table 1). 


\section{Tracheostomy in Infants With Congenital Heart Disease}

Table 2. Cox Regression Analysis With Hazard Ratio of the Risk of Tracheostomy in Infants With Congenital Heart Disease, Overall and Stratified by Follow-Up Period

\begin{tabular}{|c|c|c|c|c|c|}
\hline \multirow{2}{*}{ Variables } & \multicolumn{2}{|c|}{ Overall } & \multirow{2}{*}{$\begin{array}{c}\text { 0-3-y Follow-Up, } \\
\text { Adjusted HR (95\% CI) }\end{array}$} & \multirow{2}{*}{$\begin{array}{c}\text { 4-7-y Follow-Up, } \\
\text { Adjusted HR (95\% CI) }\end{array}$} & \multirow{2}{*}{$\begin{array}{c}\text { 8-11-y Follow-Up, } \\
\text { Adjusted HR (95\% CI) }\end{array}$} \\
\hline & Crude HR & Adjusted HR (95\% CI) & & & \\
\hline \multicolumn{6}{|l|}{ Age } \\
\hline Neonate & $1.21(0.88-1.66)$ & $1.30(0.92-1.84)$ & $1.42(0.86-2.37)$ & $2.44(1.17-5.09)$ & $1.07(0.57-2.01)$ \\
\hline Infant & 1.00 & 1.00 & 1.00 & 1.00 & 1.00 \\
\hline \multicolumn{6}{|l|}{ Sex } \\
\hline Male & $1.11(0.83-1.50)$ & $0.88(0.65-1.18)$ & $1.00(0.65-1.54)$ & $1.32(0.68-2.55)$ & $0.61(0.35-1.06)$ \\
\hline Female & 1.00 & 1.00 & 1.00 & 1.00 & 1.00 \\
\hline $\mathrm{CHD}$ & $17.87(12.18-26.21)$ & $6.67(4.40-10.10)$ & $6.86(3.68-12.81)$ & $6.51(2.71-15.59)$ & $5.82(2.83-11.98)$ \\
\hline \multicolumn{6}{|l|}{ CHD with comorbidity } \\
\hline Prematurity & $3.21(2.33-4.42)$ & $1.11(0.76-1.62)$ & $1.23(0.70-2.14)$ & $0.89(0.37-2.15)$ & $0.80(0.39-1.64)$ \\
\hline NI & $31.37(23.35-42.16)$ & $6.54(4.69-9.14)$ & 6.15 (3.79-9.99) & $6.45(3.27-12.72)$ & $7.84(4.17-14.74)$ \\
\hline CAA & $77.26(57.42-103.95)$ & $17.77(12.57-25.11)$ & $10.31(5.30-16.89)$ & $25.71(12.21-54.14)$ & $18.86(15.07-55.27)$ \\
\hline Chromosomal anomaly & $22.10(14.67-33.30)$ & $2.84(1.85-4.36)$ & $2.44(1.34-4.41)$ & $8.86(4.18-18.81)$ & $0.53(0.13-2.22)$ \\
\hline Chronic lung disease & $18.30(11.10-30.18)$ & $1.99(1.15-3.47)$ & $2.12(1.01-4.45)$ & $1.72(0.46-6.44)$ & $1.40(0.40-4.85)$ \\
\hline $\begin{array}{l}\mathrm{HR}=\text { hazard ratio } \\
\mathrm{CHD}=\text { congenital heart disease } \\
\mathrm{NI}=\text { neuromuscular impairment } \\
\mathrm{CAA}=\text { congenital airway anomaly }\end{array}$ & & & & & \\
\hline
\end{tabular}

\section{Risk of Tracheostomy in Infants With CHD}

Infants with CHD had a significantly elevated risk of tracheostomy compared with those without CHD (HR 17.87), and this remained significant after adjusting for confounders (adjusted HR 6.67) (Table 2). When stratified by follow-up period, the risk of tracheostomy decreased gradually with time (see Table 2).

\section{Probability of Tracheostomy in Infants With CHD}

A tracheostomy was more likely for those diagnosed with CHD as neonates (adjusted OR 1.72) within the first 0-3 y after diagnosis (adjusted OR 3.27) and for those with comorbid congenital airway anomaly (adjusted OR 15.25), neuromuscular impairment (adjusted OR 6.24), chronic lung disease (adjusted OR 2.29), or a chromosomal anomaly (adjusted OR 2.10) (Table 3).

\section{Mortality Risk of Tracheostomy in Infants With CHD}

Kaplan-Meier analysis revealed that the cumulative incidence of mortality in infants with CHD was significantly higher in those with tracheostomy than in those without (Fig. 1). The differences became rapidly prominent in the first $0-3$ y after CHD diagnosis but stabilized thereafter. The mortality rate was significantly higher for CHD with tracheostomy (62 of 144; 43.1\%) than without $(2,429$ of
Table 3. Multivariate Logistic Regression About the Probability of Tracheostomy in Infants With Congenital Heart Disease

\begin{tabular}{lc}
\hline \hline \multicolumn{1}{c}{ Variables } & Adjusted OR (95\% CI) \\
\hline Age at CHD diagnosis & \\
$\quad$ Neonate & $1.72(1.13-2.60)$ \\
Infant & 1.00 \\
Sex & \\
Male & $0.84(0.60-1.19)$ \\
Female & 1.00 \\
Follow-up, y & \\
$0-3$ & $3.27(2.19-4.89)$ \\
$4-7$ & $1.48(0.91-2.42)$ \\
$8-11$ & 1.00 \\
Comorbidity & \\
CAA & $15.25(10.56-22.02)$ \\
NI & $6.24(4.35-8.94)$ \\
Chronic lung disease & $2.29(1.22-4.27)$ \\
Chromosomal anomaly & $2.10(1.25-3.52)$ \\
Prematurity & $0.89(0.58-1.37)$ \\
\hline OR = odds ratio & \\
CHD = congenital heart disease & \\
CAA = congenital airway anomaly & \\
\hline
\end{tabular}

$34,799 ; 7.0 \%)$. Mortality risk was significantly elevated in infants with CHD who underwent tracheostomy compared with those who did not (HR 6.41), and this remained after adjusting for confounders (adjusted HR 3.88). When stratified by follow-up period, the mortality risk associated with tracheostomy increased with time (Table 4). 


\section{Tracheostomy in Infants With Congenital Heart Disease}

\section{Discussion}

In this large observational study, we demonstrated that subjects with CHD had a 6.67 times higher risk of tracheostomy than those without CHD. Furthermore, tracheostomies were more common among those with congenital airway anomaly and neuromuscular impairment and were most likely to be needed within the first $0-3$ y after CHD diagnosis. Mortality risk was also elevated following tra-

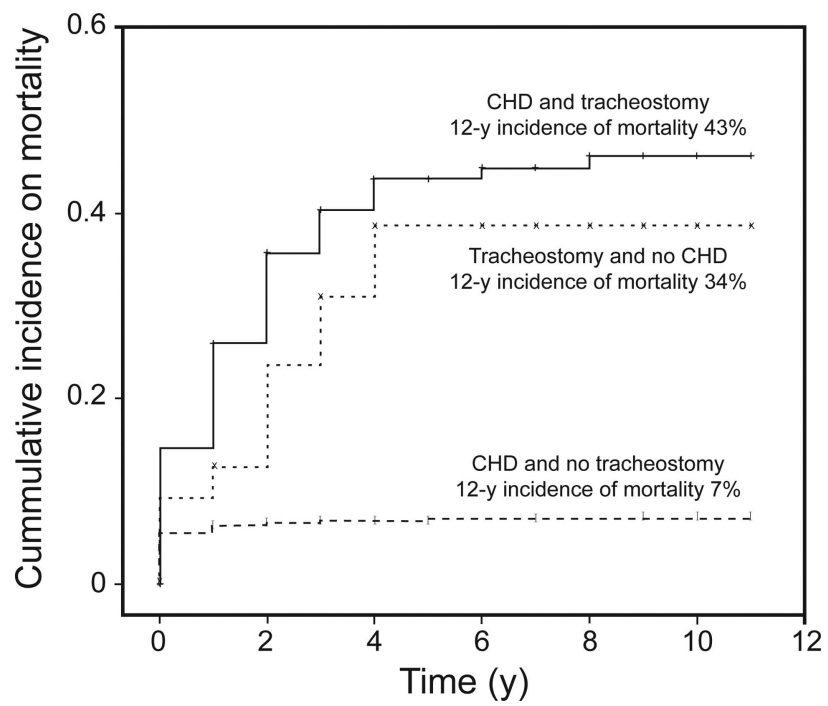

Fig. 1. Cumulative mortality incidence in infants with congenital heart disease $(\mathrm{CHD})$ with and without tracheostomy (log-rank, $P<.001)$. cheostomy in infants with CHD, with an adjusted HR of 3.88 after a mean 6.4-y follow-up period. Over time, there was a decrease in the risk of tracheostomy and an increase in the associated mortality risk for infants with CHD. The validity of our results is strengthened by the study design, which included nationwide, population-based data from multiple institutions and longitudinal follow-up.

The reported incidence of tracheostomy in children with CHD is low in the literature, ${ }^{17,18,21}$ with a rate of $0.2 \%$ among pediatric subjects undergoing cardiovascular surgery ${ }^{17}$ and $3.5 \%$ among pediatric admissions with CHD. ${ }^{21}$ In this study, the rate was $0.4 \%$ among infants with CHD. Compared with our study, previous reports tended to focus on broader pediatric populations or were hospital-based, single-institution investigations with limited numbers of participants. Our extensive data set and focus on a subgroup of infants with CHD may explain the inconsistent results.

Previous studies have often failed to explore the risk for tracheostomy in infants with CHD. We demonstrated that infants with CHD had a 6.67 times higher risk of receiving a tracheostomy, after adjusting for confounders and that the greatest risk was in the first $0-3$ y after CHD diagnosis (adjusted HR 6.86). We also illustrated that congenital airway anomaly (adjusted OR 15.25), neuromuscular impairment (adjusted OR 6.24), and the first $0-3$ y after CHD diagnosis (adjusted OR 3.27) were most strongly correlated with tracheostomy placement. The higher probability of tracheostomy may be due to the complexity of CHD, prolonged mechanical ventilation and failed extu-

Table 4. Cox Regression Analysis With Hazard Ratios for Mortality in Infants With Congenital Heart Disease, Overall and Stratified by Follow-Up Period

\begin{tabular}{|c|c|c|c|c|c|}
\hline \multirow{2}{*}{ Variables } & \multicolumn{2}{|c|}{ Overall } & \multirow{2}{*}{$\begin{array}{c}\text { 0-3-y Follow-Up, } \\
\text { Adjusted HR (95\% CI) }\end{array}$} & \multirow{2}{*}{$\begin{array}{c}\text { 4-7-y Follow-Up, } \\
\text { Adjusted HR (95\% CI) }\end{array}$} & \multirow{2}{*}{$\begin{array}{c}\text { 8-11-y Follow-Up, } \\
\text { Adjusted HR (95\% CI) }\end{array}$} \\
\hline & Crude HR & Adjusted HR (95\% CI) & & & \\
\hline \multicolumn{6}{|l|}{ Age } \\
\hline Neonate & $2.18(1.98-2.41)$ & $2.18(1.97-2.43)$ & $3.21(2.88-3.57)$ & $2.35(1.41-3.93)$ & $0.69(0.19-2.48)$ \\
\hline Infant & 1.00 & 1.00 & 1.00 & 1.00 & 1.00 \\
\hline \multicolumn{6}{|l|}{ Sex } \\
\hline Male & $1.07(0.99-1.61)$ & $1.11(1.02-1.20)$ & $1.38(1.17-1.61)$ & $1.12(0.70-1.78)$ & $0.65(0.20-2.06)$ \\
\hline Female & 1.00 & 1.00 & 1.00 & 1.00 & 1.00 \\
\hline CHD with tracheostomy & $6.41(4.98-8.25)$ & $3.88(2.96-5.08)$ & $2.06(1.56-2.71)$ & $7.19(2.42-21.38)$ & $14.76(1.46-149.69)$ \\
\hline \multicolumn{6}{|l|}{ CHD with comorbidity } \\
\hline Prematurity & $1.37(1.26-1.48)$ & $1.07(0.98-1.17)$ & $0.75(0.69-0.83)$ & $0.39(0.20-0.77)$ & $0.90(0.22-3.68)$ \\
\hline NI & $1.52(1.34-1.72)$ & $1.11(0.97-1.27)$ & $1.09(0.95-1.25)$ & $2.43(1.34-4.39)$ & $15.48(4.61-52.01)$ \\
\hline CAA & $1.86(1.61-2.16)$ & $1.47(1.25-1.72)$ & $1.37(1.17-1.61)$ & $1.31(0.59-2.93)$ & $0.48(0.05-4.83)$ \\
\hline Chromosomal anomaly & $3.91(3.46-4.43)$ & $3.74(3.30-4.24)$ & $2.21(1.95-2.52)$ & $6.33(3.44-11.65)$ & $4.01(0.83-19.35)$ \\
\hline Chronic lung disease & $1.42(1.12-1.80)$ & $1.02(0.80-1.30)$ & $0.73(0.57-0.94)$ & $4.21(1.41-12.57)$ & \\
\hline $\begin{array}{l}\mathrm{HR}=\text { hazard ratio } \\
\mathrm{CHD}=\text { congenital heart disease } \\
\mathrm{NI}=\text { neuromuscular impairment } \\
\mathrm{CAA}=\text { congenital airway anomaly }\end{array}$ & & & & & \\
\hline
\end{tabular}




\section{Tracheostomy in Infants With Congenital Heart Disease}

bation after cardiac surgery, 18,20,29,30 and comorbid chronic health conditions. ${ }^{6,10}$ Although the effect was not significant, comorbidity with prematurity seemed to decrease the probability of tracheostomy placement (adjusted OR 0.89, 95\% CI 0.58-1.37), which may be due to the co-linearity between such factors as prematurity and chronic lung disease. Further investigations into the relationships between the severity of CHD, its management, and the effects of different comorbidities by age strata may clarify these uncertainties.

Airway anomalies among pediatric patients with CHD treated with tracheostomies have been associated with mortality reductions. ${ }^{6}$ Congenital airway anomaly is believed to be significantly associated with CHD,, $31-34$ and early identification is essential for appropriate management. . $^{32,35}$ Here, we demonstrated that congenital airway anomaly was an independent risk factor for tracheostomy in infants with CHD. Tracheostomy placement may improve outcomes; therefore, timely diagnosis and optimal management of congenital airway anomaly are essential.

It has been postulated that pediatric patients with tracheostomy have an increased risk of death, ${ }^{11}$ with a mortality rate of approximately $5-8 \% .6,10,14$ Reports have also indicated that the mortality rate among pediatric subjects with CHD and a tracheostomy ranges from $18.7 \%^{6}$ to $52 \% .{ }^{20}$ In this study, we report a mortality rate of $43.1 \%$ for infants with CHD undergoing tracheostomy. Together, these results indicate that pediatric patients with $\mathrm{CHD}$ and a tracheostomy have a high mortality rate and that CHD may be an independent risk factor for increased mortality. Additional investigations are warranted to clarify the mortality risk in patients with CHD and a tracheostomy if we are to unravel the underlying mechanisms.

The critical period and prognosis for infants with CHD who have a tracheostomy have rarely been discussed. Our Kaplan-Meier analysis showed that the cumulative incidence of mortality among infants with CHD increased more steeply in the first $0-3$ y after CHD diagnosis and then stabilized. This pattern was true of subjects with and without a tracheostomy, although the magnitude was different. We also showed that infants with CHD and a tracheostomy had a 3.88 times increased mortality risk compared with those without a tracheostomy. Physicians managing patients with CHD should be aware of the elevated mortality risk of those requiring a tracheostomy and that the first $0-3 \mathrm{y}$ after diagnosis may be a critical period for the development of adverse events.

It has also been suggested that patients $\leq 1$ y old with CHD have higher mortality rates following tracheostomy placement. ${ }^{6}$ The current stratified analysis demonstrated that mortality risk increased with time among infants with CHD requiring a tracheostomy and reached 14.76 times the baseline risk during the $8-11 \mathrm{y}$ after diagnosis. The progressive increase in mortality risk may be due to un- derlying CHD, comorbidities, or tracheostomy-related complications. As the follow-up period increased, so too did the influence of tracheostomy placement. Additional research is needed to understand the differences in mortality risk during follow-up in infants with CHD and a tracheostomy.

The major strengths of this study were the populationbased design, the comprehensive coverage of CHD cases with tracheostomy in the population, and the virtual elimination of loss to follow-up. Nevertheless, several limitations are worth consideration. First, because the study was observational, it could not establish a causative link between CHD, tracheostomies, and mortality. Second, we could not clarify the phenotype, severity, and management of CHD; the presence and severity of associated pulmonary hypertension; the true indication for tracheostomy; the severity of lung disease; or the true reason for mortality from the National Health Insurance Research Database. Therefore, we could not analyze the possible relationship between these characteristics and the mortality risk. Third, because this study was conducted in Taiwan, the findings might not be valid for other populations. Additional largescale studies, with longer follow-up periods, different age strata, and multiple countries, are needed to make definitive conclusions.

\section{Conclusions}

Infants with CHD have an increased risk of tracheostomy, particularly if they have comorbid congenital airway anomaly or neuromuscular impairment. A tracheostomy is most likely to be required during the first $0-3$ y after being diagnosed with CHD. In addition, the mortality risk is significantly increased in infants with CHD and tracheostomy, and the mortality risk increases progressively with time. During the follow-up of infants with CHD, we recommend that clinicians be vigilant for the need for tracheostomy and be aware of the increased mortality risk associated with tracheostomy placement. Further studies are warranted to clarify the mechanisms underlying the risks associated with tracheostomy.

\section{ACKNOWLEDGMENTS}

This study was based, in part, on data from the National Health Insurance Research Database provided by the National Health Insurance Administration, Ministry of Health and Welfare, and managed by the National Health Research Institute. The interpretation and conclusions contained herein do not represent those of the aforementioned administration or the National Health Research Institute, Taiwan. We thank Enago for the English language review.

\section{REFERENCES}

1. Bernier PL, Stefanescu A, Samoukovic G, Tchervenkov CI. The challenge of congenital heart disease worldwide: epidemiologic and 


\section{Tracheostomy in Infants With Congenital Heart Disease}

demographic facts. Semin Thorac Cardiovasc Surg Pediatr Card Surg Annu 2010;13(1):26-34.

2. van der Linde D, Konings EE, Slager MA, Witsenburg M, Helbing WA, Takkenberg JJ, Roos-Hesselink JW. Birth prevalence of congenital heart disease worldwide: a systematic review and meta-analysis. J Am Coll Cardiol 2011;58(21):2241-2247.

3. Bernstein D. Epidemiology and genetic basis of congenital heart disease. In: Kliegman RM, Schor NF, Behrman RE, editors. Nelson textbook of pediatrics. Philadelphia: Saunders, 2011;1549.

4. Guillemaud JP, El-Hakim H, Richards S, Chauhan N. Airway pathologic abnormalities in symptomatic children with congenital cardiac and vascular disease. Arch Otolaryngol Head Neck Surg 2007;133(7): 672-676.

5. Davis GM. Tracheostomy in children. Paediatr Respir Rev 2006; 7(Suppl 1):S206-S209.

6. Berry JG, Graham RJ, Roberson DW, Rhein L, Graham DA, Zhou $\mathrm{J}$, et al. Patient characteristics associated with in-hospital mortality in children following tracheotomy. Arch Dis Child 2010;95(9):703710 .

7. Line WS Jr., Hawkins DB, Kahlstrom EJ, MacLaughlin EF, Ensley JL. Tracheotomy in infants and young children: the changing perspective 1970-1985. Laryngoscope 1986;96(5):510-515.

8. Carron JD, Derkay CS, Strope GL, Nosonchuk JE, Darrow DH. Pediatric tracheotomies: changing indications and outcomes. Laryngoscope 2000;110(7):1099-1104

9. Seddon PC, Khan Y. Respiratory problems in children with neurological impairment. Arch Dis Child 2003;88(1):75-78.

10. Lewis CW, Carron JD, Perkins JA, Sie KC, Feudtner C. Tracheotomy in pediatric patients: a national perspective. Arch Otolaryngol Head Neck Surg 2003;129(5):523-529.

11. Berry JG, Graham DA, Graham RJ, Zhou J, Putney HL, O'Brien JE, et al. Predictors of clinical outcomes and hospital resource use of children after tracheotomy. Pediatrics 2009;124(2):563-572.

12. Lawrason A, Kavanagh K. Pediatric tracheotomy: are the indications changing? Int J Pediatr Otorhinolaryngol 2013;77(6):922-925.

13. Dursun O, Ozel D. Early and long-term outcome after tracheostomy in children. Pediatr Int 2011;53(2):202-206.

14. Wood D, McShane P, Davis P. Tracheostomy in children admitted to paediatric intensive care. Arch Dis Child 2012;97(10):866-869.

15. LoTempio MM, Shapiro NL. Tracheotomy tube placement in children following cardiothoracic surgery: indications and outcomes. Am J Otolaryngol 2002;23(6):337-340.

16. Hoskote A, Cohen G, Goldman A, Shekerdemian L. Tracheostomy in infants and children after cardiothoracic surgery: indications, associated risk factors, and timing. J Thorac Cardiovasc Surg 2005; 130(4): 1086-1093.

17. Rossi AF, Fishberger S, Hannan RL, Nieves JA, Bolivar J, Dobrolet N, Burke RP. Frequency and indications for tracheostomy and gastrostomy after congenital heart surgery. Pediatr Cardiol 2009;30(3): 225-231.

18. Edwards JD, Kun SS, Keens TG, Khemani RG, Moromisato DY. Children with corrected or palliated congenital heart disease on home mechanical ventilation. Pediatr Pulmonol 2010;45(7):645-649.
19. Cotts T, Hirsch J, Thorne M, Gajarski R. Tracheostomy after pediatric cardiac surgery: frequency, indications, and outcomes. J Thorac Cardiovasc Surg 2011;141(2):413-418.

20. Challapudi G, Natarajan G, Aggarwal S. Single-center experience of outcomes of tracheostomy in children with congenital heart disease. Congenit Heart Dis 2013;8(6):556-560.

21. Maxwell BG, McMillan KN. Tracheostomy in children with congenital heart disease: a national analysis of the Kids' Inpatient Database. PeerJ 2014;2:e568.

22. Costello JP, Emerson DA, Shu MK, Peer SM, Zurakowski D, Reilly $\mathrm{BK}$, et al. Outcomes of tracheostomy following congenital heart surgery: a contemporary experience. Congenit Heart Dis 2015;10(1): E25-E29.

23. Chen YJ, Wu CY, Shen JL, Chen TT, Chang YT. Cancer risk in patients with chronic urticaria: a population-based cohort study. Arch Dermatol 2012;148(1):103-108.

24. Lin CC, Lai MS, Syu CY, Chang SC, Tseng FY. Accuracy of diabetes diagnosis in health insurance claims data in Taiwan. J Formos Med Assoc 2005;104(3):157-163.

25. Cheng CL, Kao YH, Lin SJ, Lee CH, Lai ML. Validation of the National Health Insurance Research Database with ischemic stroke cases in Taiwan. Pharmacoepidemiol Drug Saf 2011;20(3):236-242.

26. Cheng CL, Lee CH, Chen PS, Li YH, Lin SJ, Yang YH. Validation of acute myocardial infarction cases in the National Health Insurance Research Database in Taiwan. J Epidemiol 2014;24(6):500-507.

27. Mehta RP, Chesnulovitch K, Jones DT, Roberson DW. Pediatric deaths due to otolaryngologic causes: a population-based study in Massachusetts, 1990-2002. Laryngoscope 2005;115(11):1923-1929.

28. Srivastava R, Downey EC, Feola P, Samore M, Coburn L, Holubkov $\mathrm{R}$, et al. Quality of life of children with neurological impairment who receive a fundoplication for gastroesophageal reflux disease. J Hosp Med 2007;2(3):165-173.

29. Ip P, Chiu CS, Cheung YF. Risk factors prolonging ventilation in young children after cardiac surgery: impact of noninfectious pulmonary complications. Pediatr Crit Care Med 2002;3(3):269-274.

30. Shi S, Zhao Z, Liu X, Shu Q, Tan L, Lin R, et al. Perioperative risk factors for prolonged mechanical ventilation following cardiac surgery in neonates and young infants. Chest 2008;134(4):768-774.

31. van Veenendaal MB, Liem KD, Marres HA. Congenital absence of the trachea. Eur J Pediatr 2000;159(1):8-13.

32. Lee SL, Cheung YF, Leung MP, Ng YK, Tsoi NS. Airway obstruction in children with congenital heart disease: assessment by flexible bronchoscopy. Pediatr Pulmonol 2002;34(4):304-311.

33. Inwald DP, Roebuck D, Elliott MJ, Mok Q. Current management and outcome of tracheobronchial malacia and stenosis presenting to the paediatric intensive care unit. Intensive Care Med 2001;27(4): 722-729.

34. Elliott M, Roebuck D, Noctor C, McLaren C, Hartley B, Mok Q, et al. The management of congenital tracheal stenosis. Int J Pediatr Otorhinolaryngol 2003;67(Suppl 1):S183-S192.

35. Healy F, Hanna BD, Zinman R. Pulmonary complications of congenital heart disease. Paediatr Respir Rev 2012;13(1):10-15. 